\title{
Information
}

\section{General meeting of the Division of Chemistry and Materials Sciences of the Russian Academy of Sciences}

General meeting of the Division of Chemistry and Materials Sciences of the Russian Academy of Sciences was held on March 28, 2018, at the N. D. Zelinsky Institute of Organic Chemistry of the RAS.

The report on the activity of the Division of Chemistry and Materials Sciences of the RAS in 2017 was presented by Secretary Academician of the Division, Academician of the RAS M. P. Egorov.

The following candidates were nominated for the rank "Professor of the RAS": T. V. Basova (A. V. Nikolaev Institute of Inorganic Chemistry, Siberian Branch of the RAS, Novosibirsk), G. V. Zyryanov (I. Ya. Postovsky Institute of Organic Synthesis, Ural Branch of the RAS, Yekaterinburg), S. S. Karlov (M. V. Lomonosov Moscow State University), D. V. Konarev (Institute of Problems of Chemical Physics of the RAS, Chernogolovka), A. A. Korlyukov (A. N. Nesmeyanov Institute of Organoelement Compounds of the RAS), A. G. Mazhuga (M. V. Lomonosov Moscow State University), A. A. Polotskii (Institute of Macromolecular Compounds of the RAS, St-Petersburg), A. Yu. Fedorov (N. I. Lobachevsky State University of Nizhny Novgorod), and $V$. N. Khrustalev (Joint Institute for Chemical Research, Russian People's Friendship University).

The General Meeting of the Division of Chemistry and Materials Sciences of the RAS congratulated researchers who have won State and name awards. The Prize of the Russian Federation Government in science and technology for the development, industrial production, and largescale implementation of high-performance dual-purpose catalysts for the synthesis of chemicals, production of process gases, and purification of discharge gases at chemical, petrochemical, metallurgical, mechanical engineering, food, nuclear, defense, medicinal, and other plants and in the housing and utilities sector was awarded to the supervisor of the research Academician of the RAS V. V. Lunin (President of the Department of Chemistry, M. V. Lomonosov Moscow State University). The Prize of the Russian Federation Government in science and technology was awarded to the research team including Professor A. A. Kuznetsov (N. S. Enikolopov Institute of Synthetic Polymer Materials of the RAS) for solving problems of protection of aquatic environment from contamination by wide implementation of lubricant-free bearings based on new materials for power engineering equipment. The N. D. Zelinsky Prize of 2017 was awarded to Professor V. P. Krasnov (I. Ya. Postovsky Institute of Organic Synthesis, Ural Branch of the RAS) for the series of studies "Kinetic resolution of racemic amines by diastereoselective acylation. Theoretical and practical aspects"; V. A. Kargin Prize was awarded to Professor V.A. Davankov (A. N. Nesmeyanov Institute of Organoelement Compounds of the RAS) for the work "Hyper-cross-linked polymers"; V. A. Koptyug Prize was awarded to Academician of the RAS $V$. V. Lunin for the series of works "Development of new catalysts for environmental catalysis".

The scientific report "New universal law of photoluminescence" was presented by Corresponding Member of the RAS V. F. Razumov.

Corresponding Member of the RAS N.P. Tarasova reported on proclaiming the International Year of the Periodic Table of Chemical Elements in 2019 by the United Nation Organization and on the events planned in relation to the 150-year anniversary of the Periodic Table.

Published in Russian in Izvestiya Akademii Nauk. Seriya Khimicheskaya, No. 5, pp. 0927-0930, May, 2018. 